\title{
Femoral artery homograft for coronary artery plasty following arterial switch operation
}

\author{
Ralph Mosca, MD, ${ }^{\mathrm{a}}$ David Chen, MD, ${ }^{\mathrm{a}}$ Dan Halpern, MD, ${ }^{\mathrm{b}}$ Charles Ma, MD, ${ }^{\mathrm{a}}$ Jodi Feinberg, NP,
} Puneet Bhatla, MD, ${ }^{b}$ and T. K. Susheel Kumar, MD, ${ }^{a}$ New York, NY

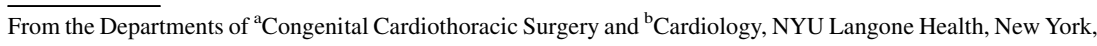
NY.

Disclosures: The authors reported no conflicts of interest.

The Journal policy requires editors and reviewers to disclose conflicts of interest and to decline handling or reviewing manuscripts for which they may have a conflict of interest. The editors and reviewers of this article have no conflicts of interest.

Received for publication July 29, 2020; revisions received July 29, 2020; accepted for publication Aug 10, 2020; available ahead of print Aug 15, 2020.

Address for reprints: Ralph Mosca, MD, Department of Congenital Cardiothoracic Surgery, NYU Langone Health, New York, NY 10016 (E-mail: Ralph.Mosca@nyulangone.org).

JTCVS Techniques 2020;4:232-4

2666-2507

Copyright (C 2020 The Authors. Published by Elsevier Inc. on behalf of The American Association for Thoracic Surgery. This is an open access article under the CC BY-NC-ND license (http://creativecommons.org/licenses/bync-nd/4.0/).

https://doi.org/10.1016/j.xjtc.2020.08.013

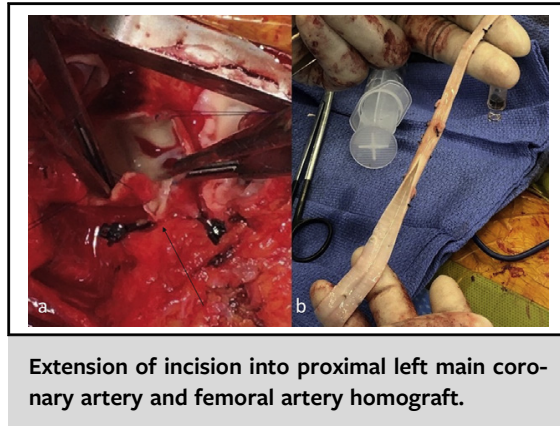

CENTRAL MESSAGE

Surgical intervention for stenosis in single coronary artery system following arterial switch can be a high risk procedure. Femoral artery homograft is a suitable choice for coronary artery plasty.

See Commentaries on pages 235 and 237. phy angiogram (CTA) revealed a single coronary artery that arose from the right facing sinus and bifurcated into a widely patent and dominant right coronary artery and a left main coronary artery (LMCA) that was severely stenosed at its origin (Figure 1, A). Percutaneous angioplasty of the proximal LMCA with possible stenting was not considered a safe or durable option in view of his young age and the risk of occlusion ("jailing") of the adjacent right coronary artery. Surgical options included LMCA ostioplasty, bypass grafting to LMCA, and unroofing of adjacent wall of the LMCA into the aorta. Following a detailed discussion and consent, the patient was taken to the operating room for coronary artery plasty on cardiopulmonary bypass (CPB).

The patient was placed on CPB via peripheral cannulation. Following chest re-entry, the main pulmonary artery was transected to gain access to the ascending aorta. An aortotomy was performed about $1 \mathrm{~cm}$ above the origin of the single coronary artery after myocardial arrest. Although coronary CTA had suggested that an unroofing procedure was possible, we noticed considerable gap between the coronary artery and the wall of the aorta. In addition, the oblique course of the artery with respect to the aortic wall made this option unfeasible. We decided against coronary artery bypass grafting because of the young age of the patient. The aortotomy incision was carried into the orifice of the

single coronary artery and the narrowed opening of the LMCA was identified. The incision was then continued across the LMCA ostium well past the stenosis. A thawed 6-mm femoral artery homograft was fashioned into an oval-shaped patch. This was used to augment the narrowed segment of LMCA, the area of bifurcation, and opening of the single coronary artery into the aorta using continuous 7.0 PROLENE (Figure 2). This patch was carried onto the ascending aorta for a short distance and the aortotomy was closed.

Following reconstruction of the main pulmonary artery, the patient was weaned off CPB without issues and both coronary arteries appeared widely patent on transesophageal echocardiogram with good biventricular contractility. The postoperative course was uneventful, and he was discharged on aspirin. He is asymptomatic at 7 months' follow-up. Coronary CTA done 6 months after the procedure demonstrates a patent LMCA (Figure $1, B$ ). This case report does not contain any patient identifiers and is hence exempt from institutional review board review as per institutional guidelines. 


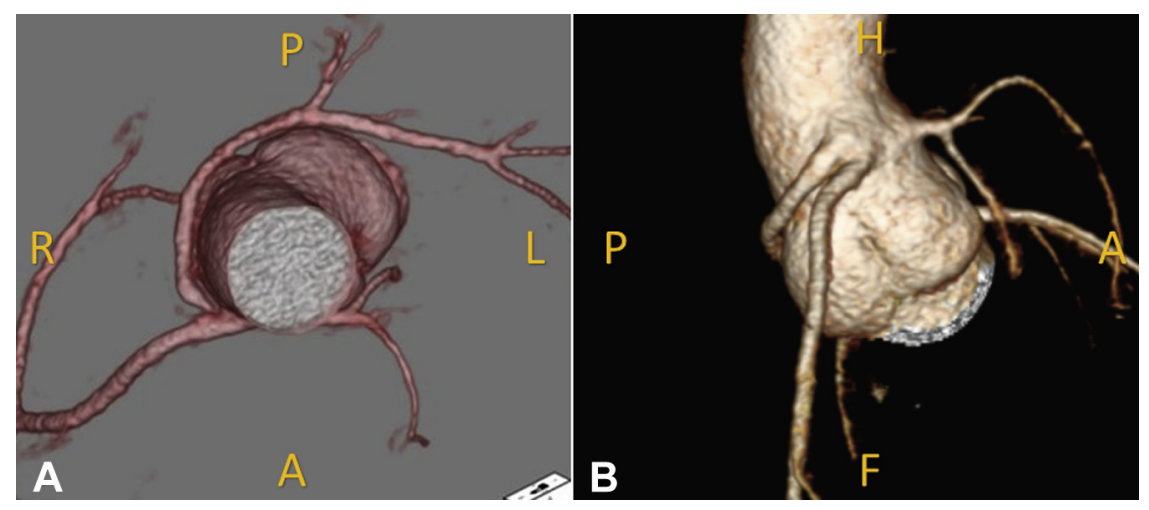

FIGURE 1. Coronary computed tomography angiogram, 3-dimensional reconstruction (A) showing stenosis of the proximal segment of the left main coronary artery as it emerges from the single right coronary artery and 3-dimensional reconstruction (B) showing widely patent left main coronary artery following reconstruction.

\section{DISCUSSION}

Coronary artery narrowing in the form of ostial stenosis or kinking is a well-recognized complication of ASO and presents in a bimodal pattern. ${ }^{1,2}$ Risk factors for coronary artery stenosis following ASO include intramural coronary artery and single coronary artery, as highlighted previously. ${ }^{3}$ In single coronary artery patterns, the coronary arteries arise from a common origin and extend in opposite directions, thereby increasing the likelihood of stretching or kinking of one or both of them following transfer during ASO. ${ }^{4}$

Surgical ostial plasty usually involves extension of the aortotomy incision across the area of stenosis into the coronary artery and augmentation of the coronary artery using a patch. ${ }^{1-3,5}$ Various types of patches have been described, including native and treated pericardium, bovine pericardium, and pulmonary homograft. Selection of the patch is crucial to avoid restenosis, as has been well described with the use of bovine pericardium. ${ }^{2}$ In a redo situation, the pericardium and autologous tissues such as aorta and pulmonary artery can be sparse and fibrotic, making them less suitable for coronary artery plasty. Care must also be taken to avoid ballooning or kinking of the onlay patch, especially in the zone of bifurcation where the LMCA joins the right coronary artery and coronary opening in the aorta. Femoral artery homograft is well suited for this situation, as it has a contour and tissue quality that matches that of the coronary artery. It is hemostatic and the natural endothelial lining makes it less likely thrombogenic compared with artificial patches. Any intervention to treat stenosis involving single coronary artery system has the potential to jeopardize the entire coronary circulation. The procedure should not only correct the narrowed segment of the coronary artery but also preserve the integrity of the bifurcation and opening of the single coronary artery. A femoral artery homograft is a suitable choice in this situation, although it is expensive and longer-term results associated with its use are unknown.

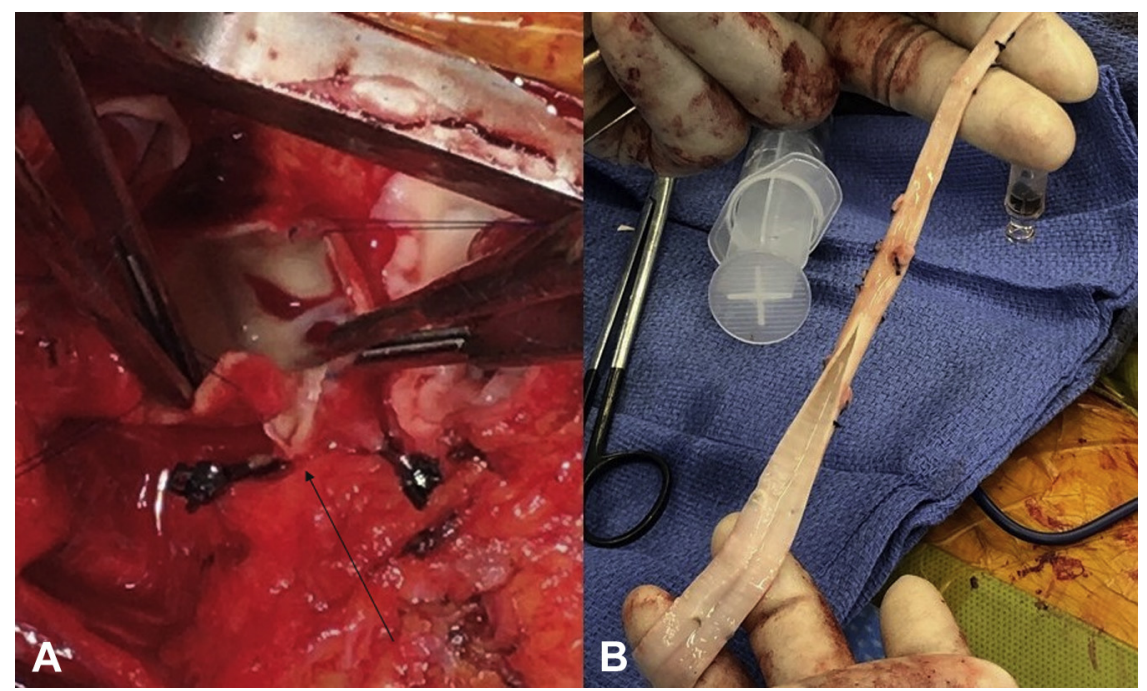

FIGURE 2. Extension of incision into proximal left main coronary artery and femoral artery homograft. A, Intraoperative photograph. B, Femoral artery homograft. Arrow indicates opened distal end of left main coronary artery, controlled with Heifitz surgical clip. 


\section{References}

1. Mavroudis C, Stewart RD, Backer CL, Rudra H, Vargo P, Jacobs ML. Reoperative techniques for complications after arterial switch. Ann Thorac Surg. 2011;92: 1747-54; discussion 54-5.

2. Jung JC, Kwak JG, Kim ER, Bang JH, Min J, Lim JH, et al. Reoperation for coronary artery stenosis after arterial switch operation. Interact Cardiovasc Thorac Surg. 2018;27:169-76.
3. Tsuda T, Bhat AM, Robinson BW, Baffa JM, Radtke W. Coronary artery problems late after arterial switch operation for transposition of the great arteries. Circ J. 2015;79:2372-9.

4. Pasquali SK, Hasselblad V, Li JS, Kong DF, Sanders SP. Coronary artery pattern and outcome of arterial switch operation for transposition of the great arteries: a meta-analysis. Circulation. 2002;106:2575-80.

5. Prifti E, Bonacchi M, Luisi SV, Vanini V. Coronary revascularization after arterial switch operation. Eur J Cardiothorac Surg. 2002;21:111-3. 